\title{
Is high myopia a risk factor for visual field progression or disk hemorrhage in primary open-angle glaucoma?
}

This article was published in the following Dove Press journal:

Clinical Ophthalmology

4 April 2017

Number of times this article has been viewed

\author{
Koji Nitta' \\ Kazuhisa Sugiyama ${ }^{2}$ \\ Ryotaro Wajima' \\ Gaku Tachibana' \\ 'Department of Ophthalmology, \\ Fukui-ken Saiseikai Hospital, Fukui, \\ ${ }^{2}$ Department of Ophthalmology, \\ Kanazawa University Graduate School \\ of Medical Science, Kanazawa, Japan
}

Correspondence: Koji Nitta Department of Ophthalmology, Fukui-ken Saiseikai Hospital, 7-I Wadanaka-machi Funabashi, Fukui 918-8503, Japan

$\mathrm{Tel}+8 \mid 77623$ IIII

Fax +8I 776287754

Email nitta.koji700I@fukui.saiseikai.or.jp
Purpose: The purpose of this study was to clarify differences between highly myopic and non-myopic primary open-angle glaucoma (POAG) patients, including normal-tension glaucoma patients.

Patients and methods: A total of 269 POAG patients were divided into two groups: patients with $\geq 26.5 \mathrm{~mm}$ of axial length (highly myopic group) and patients with $<24.0 \mathrm{~mm}$ of axial length (non-myopic group).

Results: We analyzed 53 highly myopic and 93 non-myopic POAG patients. Age at first visit of the highly myopic group was significantly less than that of the non-myopic group $(P<0.0001)$. Baseline intraocular pressures (IOPs) showed no significant differences. Follow-up IOPs of the non-myopic group were significantly lower than those of the highly myopic group $(P=0.0009)$. According to the mean deviation definition of progression, the cumulative probability of nonprogression of visual field (VF) loss was significantly greater in the highly myopic group (10-year survival rate, $73.7 \% \pm 6.8 \%$ ) than in the non-myopic group (10-year survival rate, $46.3 \% \pm 5.8 \%$; log-rank test, $P=0.0142$ ). The occurrence of disk hemorrhage (DH) in the non-myopic group $(1.60 \pm 3.04)$ was significantly greater than that in the highly myopic group $(0.93 \pm 2.13, P=0.0311)$. The cumulative probability of DH was significantly lower in the highly myopic group (10-year survival rate, $26.4 \% \pm 5.4 \%$ ) than in the non-myopic group (10-year survival rate, $47.2 \% \pm 6.6 \%$, $P=0.0413$ ).

Conclusion: Highly myopic POAG is considered as a combination of myopic optic neuropathy and glaucomatous optic neuropathy (GON). If GON is predominant, it has frequent $\mathrm{DH}$ and more progressive VF loss. However, when the myopic optic neuropathy is predominant, it has less DH and less progressive VF loss.

Keywords: myopic glaucoma, disk hemorrhage, open-angle glaucoma, visual field defect progression, high myopia

\section{Introduction}

Meta-analyses of epidemiological surveys have reported that myopia is a risk factor for glaucoma. The odds ratio of glaucoma with high myopia is an average of 2.46 (1.93-3.15). ${ }^{1-11}$ The Tajimi Study, a Japanese population-based survey of glaucoma, reported that intraocular pressure (IOP), myopia, and age were significant risk factors for primary open-angle glaucoma (POAG), including normal-tension glaucoma (NTG). ${ }^{6}$ There have been numerous explanations for the possible relationship between myopic eyes and glaucoma. Fong et al ${ }^{12}$ reported that myopia affects the lamina cribrosa with elongation of the axial length. Progressive tilting of the optic disk with a nasal shift of the temporal optic disk margin and simultaneous development/enlargement of 
peripapillary atrophy (PPA) occur in childhood with myopic shift. These findings indicate that the lamina cribrosa, thought to be a principal site of glaucomatous damages, also shifts in the nasal direction in eyes with a tilted disk. This myopic tilting of the optic disk may generate tensile stretch on the temporal side of the lamina cribrosa and the retinal ganglion cell axons. Furthermore, direct damage to the retinal nerve fibers caused by a sharp angle of scleral bending, such as mechanical damage and excessive tension to the retinal nerve fibers, is one of the mechanisms by which visual field (VF) defects occur in highly myopic eyes. ${ }^{13}$

In myopic glaucoma, the optic disk is secondarily enlarged by elongation of the eyeball, leading to extension and thinning of the lamina cribrosa, and increased sensitivity to changes in IOP. ${ }^{14-18}$

Jonas and Budde ${ }^{15}$ reported that myopic eyes often suffer from glaucoma because of a rapid pressure slope between the ocular space and cerebrospinal space by thinning of the lamina cribrosa. They reported that the calculated translamina cribrosa pressure difference showed a better correlation with glaucoma and the amount of glaucomatous optic neuropathy (GON) in POAG and NTG patients. ${ }^{19}$ Recent studies have clarified these differences in clinical characteristics between highly myopic and non-myopic glaucomatous eyes. Yoshino et $\mathrm{al}^{20}$ reported that the rate of progression of VF defects was similar among POAG patients with high myopia and non-high myopia who were under treatment. Yamada et al investigated the relationship between the microstructure of the PPA $\beta$-zone that was classified on the basis of the presence or absence of Bruch's membrane (BM). They suggested that the PPA ${ }_{+\mathrm{BM}}$ width may be an important risk factor for VF field progression in POAG, including high myopia, and the PPA ${ }_{-B M}$ width may have a protective effect for VF progression in this type of POAG. ${ }^{21}$

Because the percentage of myopia, especially high myopia, is high in Asian populations, ${ }^{22,23}$ it is important to better understand the relationships between high myopia and the degree of VF defect progression in patients with glaucoma. Myopic glaucoma cases may have both myopic changes and glaucomatous changes. Therefore, to clarify the effects of high myopia, we analyzed the clinical features of POAG patients with high myopia, with special attention to the presence of disk hemorrhage (DH) over a long follow-up period.

\section{Patients and methods}

This study protocol was reviewed and approved by the institutional review board of Fukui-ken Saiseikai Hospital. Because of the retrospective nature of the study, the committee waived the requirement for patient informed consent. All study procedures adhered to the tenets of the Declaration of Helsinki.

\section{Patients}

We retrospectively reviewed the records of consecutive patients who were diagnosed to have POAG, including NTG, in our hospital from 1997 to 2014 at the Glaucoma Service in the Department of Ophthalmology of Fukui-ken Saiseikai Hospital. Over the entire follow-up period, only one ophthalmologist (KN) followed up all patients.

The diagnostic criteria for POAG were, 1) normal open angle; 2) glaucomatous changes in the VF with optic nerve cupping; and 3) the absence of other optic neuropathies. POAG was diagnosed according to the guidelines of the Japan Glaucoma Society ${ }^{24}$ and the European Glaucoma Society. ${ }^{25}$

Eyes were included in this study when they met all the following criteria:

1. POAG diagnosed at the Fukui-ken Saiseikai Hospital and followed up for $>3$ years at 2-month intervals by the same examiner $(\mathrm{KN})$;

2. visual acuity $>20 / 20$ during the study period, and data available until cataract surgery due to cataract progression;

3. eyes with clear fundus photography at baseline and at every follow-up; and

4. in cases when both eyes met the enrollment criteria, only the right eye was selected for analysis.

Eyes were excluded in this study when they met all the following criteria:

1. a combination of congenital optic disk anomalies or retinal diseases, including pathological myopia;

2. the possibility of other optic nerve diseases, ${ }^{26}$

3. intracranial lesions or trauma possibly associated with VF defects;

4. eyes with previous laser treatments or ocular surgeries except for cataract surgery at baseline; and

5. the number of VF tests $<7$.

Patients were examined every 2 months. During these visits, all patients underwent a complete ophthalmic examination, including measurement of uncorrected and best-corrected visual acuities using the 5-m Landolt chart, slit-lamp biomicroscopy, IOP measurements using a Goldmann applanation tonometer, dilated stereoscopic fundus examination of the optic nerve, stereo disk photography with a 3-Dx simultaneous stereo disk camera (Kowa, Nagoya, Japan), and standard automated perimetry (SAP) using a Humphrey 750 Visual Field Analyzer (HFA; Carl Zeiss Meditec, Dublin, CA, USA).

SAP was conducted at intervals of 3-6 months. Mean deviation (MD) was measured using the Central 30-2 Full 
Threshold program of the Humphrey 750 Visual Field Analyzer or standard strategies of the Swedish Interactive Threshold Algorithm. The criteria for a reliable SAP were both a false positive and false negative $\leq 33 \%$ and a fixation loss $<20 \%$. The progression rate of VF defects was evaluated by the MD slope of the HFA. Linear regression analysis was performed using a Windows-based personal computer program, HFA Files, version 5 (Beeline Office, Tokyo, Japan), to calculate the MD slope. Any reliable results as described earlier were included in the analyses.

Refraction was measured with an autorefractor-keratometer (ARK-900; Nidek, Gamagori, Japan). Axial length was measured using the IOL Master (Carl Zeiss Meditec, Dublin, CA, USA). To clarify the effects of high myopia, we divided our cases into two groups comprising eyes with an axial length $\geq 26.5 \mathrm{~mm}$ (highly myopic group) and eyes with an axial length $<24.0 \mathrm{~mm}$ (non-myopic group). There are many cases that our group followed up for the long term in this research. As a result, $27.4 \%$ of all cases were cataract surgeries during follow-up. The authors adopted the axial length for an evaluation of the refraction, because the cases existed, where a refraction state changed in post-cataract surgery existed.

DH was defined as an isolated hemorrhage seen in the optic disk tissue or in the peripapillary retina that reached the disk rim. Fundus photographs including stereoscopic images were taken at every visit to confirm the existence of DH. The data were analyzed using the Kaplan-Meier life table method to calculate the cumulative probabilities of DH occurrence. When the first occurrence of DH was observed, the follow-up evaluation was assumed to have reached its end point. The survival curves were compared using the log-rank test.

The VF loss progression was judged to have reached its end point when the perimetric progression definition was first detected, involving $>3$ decibels demonstrated twice during the follow-up period compared with two baseline values. Any perimetric result with an artifact was excluded. The data were analyzed using the Kaplan-Meier life table method to calculate the cumulative probabilities of a stable VF.

Statistical analyses were performed using SPSS statistical software, version 16.0 for Windows (SPSS Inc., Chicago, IL, USA). The chi-square test was used for comparison of sex differences. Other parameters were compared using the Mann-Whitney $U$ test. The survival curves were compared using the log-rank test. A $P$-value $<0.05$ was considered statistically significant.

\section{Results}

A total of 146 eyes of 269 POAG patients satisfied both the enrollment and exclusion criteria and were analyzed.
Of the enrolled eyes, 53 patients were highly myopic (age, $51.1 \pm 9.9$ years) and 93 patients were non-myopic (62.6 \pm 10.2 years). Age at first visit of the highly myopic group was significantly less than that of the non-myopic group $(P<0.0001)$. The mean follow-up period was 10.6 years and 12.2 years (highly myopic group versus non-myopic group, respectively). A comparison of clinical background data between the two groups is shown in Table 1 .

Table I Clinical features in the non-myopic group and highly myopic group

\begin{tabular}{|c|c|c|c|}
\hline & $\begin{array}{l}\begin{array}{l}\text { Non-myopic } \\
\text { group }\end{array} \\
\mathrm{AL}<24.0 \mathrm{~mm} \\
93 \text { eyes }\end{array}$ & $\begin{array}{l}\text { Highly } \\
\text { myopic group } \\
\mathrm{AL} \geq 26.5 \mathrm{~mm} \\
53 \text { eyes }\end{array}$ & $P$-value \\
\hline \multicolumn{2}{|c|}{ Age at first visit (years) } & & $<0.000 \mathrm{I}$ \\
\hline Mean \pm SD & $62.6 \pm 10.2$ & $51.1 \pm 9.9$ & \\
\hline Range & $27-85$ & $28-74$ & \\
\hline Sex (male/female) & $36 / 57$ & $40 / 13$ & $<0.000$ I \\
\hline \multicolumn{2}{|l|}{ Refractive error (D) } & & $<0.0001$ \\
\hline Mean \pm SD & $-0.0 \pm 1.4$ & $-8.6 \pm 2.8$ & \\
\hline Range & 3.25 to -5.5 & -3.5 to -16.5 & \\
\hline \multicolumn{2}{|l|}{ Axial length (mm) } & & $<0.000$ I \\
\hline Mean \pm SD & $23.0 \pm 0.7$ & $27.6 \pm 1.0$ & \\
\hline Range & $21.39-23.99$ & $26.50-31.73$ & \\
\hline \multicolumn{2}{|c|}{ Follow-up period (years) } & & 0.0406 \\
\hline Mean \pm SD & $12.2 \pm 4.0$ & $10.6 \pm 4.1$ & \\
\hline Range & $5.2-21.2$ & $5.5-18.7$ & \\
\hline \multicolumn{2}{|c|}{ Baseline IOP $(\mathrm{mmHg})$} & & 0.0636 \\
\hline Mean \pm SD & $16.3 \pm 4.5$ & $17.8 \pm 4.8$ & \\
\hline Range & $9-32$ & $10.3-35$ & \\
\hline \multicolumn{2}{|c|}{ Follow-up IOP $(\mathrm{mmHg})$} & & 0.0009 \\
\hline Mean \pm SD & $12.8 \pm 2.5$ & $13.8 \pm 2.3$ & \\
\hline Range & $8.5-26.9$ & $7.2-20.4$ & \\
\hline \multicolumn{2}{|l|}{ IOP reduction (\%) } & & 0.8823 \\
\hline Mean \pm SD & $17.7 \pm 16.1$ & $18.7 \pm 16.8$ & \\
\hline Range & $-32-49$ & $-18-79$ & \\
\hline \multicolumn{2}{|c|}{ IOP fluctuation $(\mathrm{mmHg})$} & & 0.0099 \\
\hline Mean \pm SD & $7.6 \pm 3.2$ & $6.2 \pm 1.6$ & \\
\hline Range & $3-20$ & $3-12$ & \\
\hline \multicolumn{2}{|c|}{ Central corneal thickness $(\mu \mathrm{m})$} & & 0.4029 \\
\hline Mean \pm SD & $538.7 \pm 35.0$ & $546.3 \pm 37.1$ & \\
\hline Range & $44|-6| 4$ & $438-644$ & \\
\hline \multicolumn{2}{|c|}{ Number of visual field tests } & & 0.0171 \\
\hline Mean \pm SD & $24.0 \pm 8.7$ & $20.5 \pm 7.3$ & \\
\hline Range & $9-48$ & $9-36$ & \\
\hline \multicolumn{2}{|l|}{ Baseline MD (dB) } & & 0.2229 \\
\hline Mean \pm SD & $-6.12 \pm 5.14$ & $-7.72 \pm 6.21$ & \\
\hline Range & I.5I to -26.66 & -0.05 to -21.22 & \\
\hline \multicolumn{2}{|l|}{ Final MD (dB) } & & 0.9919 \\
\hline Mean $\pm S D$ & $-10.22 \pm 7.33$ & $-10.29 \pm 7.42$ & \\
\hline Range & 0.88 to -29.92 & -0.30 to -26.34 & \\
\hline \multicolumn{2}{|c|}{ MD slope (dB/year) } & & 0.0183 \\
\hline Mean \pm SD & $-0.383 \pm 0.547$ & $-0.192 \pm 0.275$ & \\
\hline Range & 0.35 to -3.65 & 0.33 to -0.93 & \\
\hline \multicolumn{2}{|l|}{$\mathrm{DH}$ number } & & 0.0311 \\
\hline Mean \pm SD & $1.60 \pm 3.04$ & $0.93 \pm 2.13$ & \\
\hline Range & $0-19$ & $0-12$ & \\
\hline
\end{tabular}

Abbreviations: $A L$, axial length; $D$, diopters; IOP, intraocular pressure; $M D$, mean deviation; $\mathrm{dB}$, decibel; $\mathrm{DH}$, disk hemorrhage. 
Refractive error of the highly myopic group was significantly more myopic than that of the non-myopic group ( $-8.6 \pm 2.8$ diopters [D] versus $-0.0 \pm 1.4 \mathrm{D}$, respectively; $P<0.0001)$. Axial length of the highly myopic group was significantly longer than that of the non-myopic group (27.6 $\pm 1.0 \mathrm{~mm}$ versus $23.0 \pm 0.7 \mathrm{~mm}$, respectively; $P<0.0001$ ). Baseline IOP showed no significant difference between the two groups (highly myopic group, $17.8 \pm 4.8 \mathrm{mmHg}$ versus nonmyopic group, $16.3 \pm 4.5 \mathrm{mmHg}$, respectively; $P=0.0636$ ). The follow-up IOPs of the non-myopic group were significantly lower than those of the highly myopic group $(12.8 \pm 2.5 \mathrm{mmHg}$ versus $13.8 \pm 2.3 \mathrm{mmHg}$, respectively; $P=0.0009)$. IOP fluctuations of the non-myopic group were significantly higher than those of the highly myopic group $(7.6 \pm 3.2 \mathrm{mmHg}$ versus $6.2 \pm 1.6 \mathrm{mmHg}$, respectively; $P=0.0099$ ).

The MD slope of the non-myopic group was significantly greater than that of the highly myopic group $(-0.383 \pm 0.547 \mathrm{~dB} /$ year versus $-0.192 \pm 0.275 \mathrm{~dB} /$ year, respectively; $P=0.0183$ ). According to the MD definition of progression, the cumulative probability of non-progression of VF loss was significantly greater in the highly myopic group (10-year survival rate, $73.7 \% \pm 6.8 \%$ ) than in the non-myopic group (10-year survival rate, $46.3 \% \pm 5.8 \%$; log-rank test, $P=0.0142$; Figure 1). The occurrence of DH in the non-myopic group (1.60 \pm 3.04$)$ was significantly greater than that in the highly myopic group $(0.93 \pm 2.13, P=0.0311)$. The cumulative probability of DH was significantly lower in the highly myopic group (10-year survival rate, $26.4 \% \pm 5.4 \%$ ) than in the non-myopic group (10-year survival rate, $47.2 \% \pm 6.6 \%$, $P=0.0413$; Figure 2).

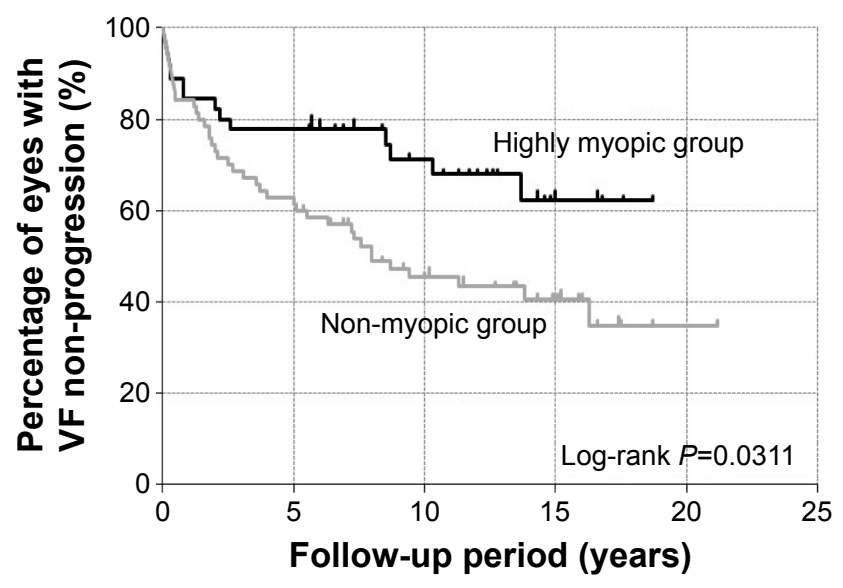

Figure I The cumulative probability of non-progression of VF loss in the highly myopic group and the non-myopic group.

Notes: The cumulative probability of non-progression of VF loss was significantly greater in the highly myopic group (10-year survival rate, $73.7 \% \pm 6.8 \%)$ than in the non-myopic group ( 10 -year survival rate, $46.3 \% \pm 5.8 \%$; log-rank test, $P=0.0142$ ). Abbreviation: VF, visual field.

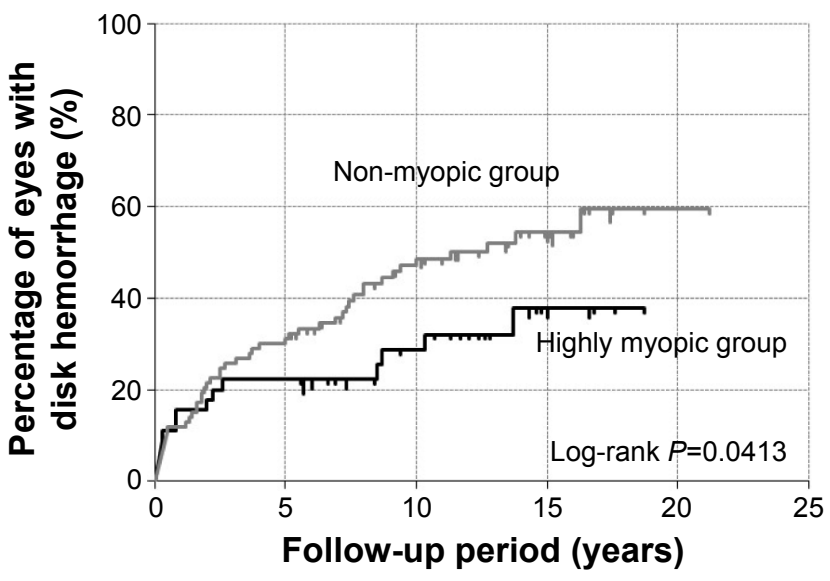

Figure 2 The cumulative probability of occurrence of $\mathrm{DH}$ in the highly myopic group and the non-myopic group.

Notes: The cumulative probability of $\mathrm{DH}$ incidences was significantly greater in the non-myopic group (10-year survival rate, $47.2 \% \pm 6.6 \%)$ than in the highly myopic group ( 10 -year survival rate, $26.4 \% \pm 5.4 \%$; log-rank test, $P=0.0413$ ).

Abbreviation: $\mathrm{DH}$, disk hemorrhage.

\section{Discussion}

We divided our cases into two groups involving a group with $\geq 26.5 \mathrm{~mm}$ of axial length (highly myopic group) and a group with $<24.0 \mathrm{~mm}$ of axial length (non-myopic group). In 2,514 Japanese schoolchildren from 7 years to 12 years of age, spherical equivalents of refraction were negatively correlated with the axial length $(y=-0.404 x+23.43, r=-0.640$, $P<0.0001) .{ }^{27}$ The mean axial length in healthy Japanese controls was $23.3 \mathrm{~mm}$. Therefore, we defined the non-myopic group as those with eyes $<24.0 \mathrm{~mm}$ of axial length. ${ }^{28}$

The optic disk becomes tilted as the axial length elongates in early adulthood. When posterior staphyloma develops in early middle age, optic disk structural changes also occur. These changes may result in the fragility of the supporting tissue in the lamina cribrosa and in dynamic imbalances due to structural changes in the environment of the optic nerve head. This may lead to myopic optic neuropathy with GON..$^{13,15}$ Therefore, the structural change in the highly myopic group may be different from the structural change in the non-myopic glaucoma group. As a result, the ages at first visit of the highly myopic group were significantly less than those of the non-myopic group in the present study.

The MD slope of the highly myopic group was $-0.192 \mathrm{~dB} /$ year. The mean progression rate of the total VF in Japanese open-angle glaucoma patients was $-0.41 \mathrm{~dB} /$ year using the MD slope. ${ }^{29}$ The cumulative probability of non-progression of VF loss was significantly greater in the highly myopic group than in the non-myopic group. If highly myopic glaucoma patients are older than late middle age, deformation of the peripapillary sclera by a tilted disk and elongation of 
axial length could be complete. ${ }^{13,15}$ Therefore, the rate of VF loss progression in highly myopic glaucoma patients may be slow. The myopia-related structural changes may be more confused on whether glaucoma is present or not. Thus, some myopic eyes with VF defects tend to be misdiagnosed as glaucoma, and this might have led to the conclusion of the significantly faster MD slope of the non-myopic group than that of the highly myopic group. ${ }^{30}$

The occurrence of DH in the non-myopic group was significantly greater than that in the highly myopic group. The cumulative probability of DH incidences was significantly lower in the myopic group than in the non-myopic group. $\mathrm{DH}$ has been reported to be a significant negative prognostic factor in patients with glaucoma. As the occurrence of $\mathrm{DH}$ increases, the MD slope $(r=-0.263, P=0.0056)$ and the rate of retinal nerve fiber layer defects enlargement $(r=0.410$, $P<0.0001)$ significantly increase. ${ }^{31}$ Park et al ${ }^{32}$ reported that age and baseline IOP were significantly related to MD slope in the myopic group (eyes with $\geq 24.0 \mathrm{~mm}$ of axial length), which was only due to the presence of $\mathrm{DH}$ in the non-myopic group (eyes with $<24.0 \mathrm{~mm}$ of axial length).

DH has been reported to be a significant negative prognostic factor in patients with glaucoma and may be a sign of progressive damage of retinal nerve fiber layer, leading to the functional deterioration of the $\mathrm{VF}^{33-43}$

We consider that the lower incidence of DH could be related to the slower rate of VF deterioration in highly myopic eyes.

There are potential limitations to this study. First, it was a hospital-based study with inclusion criteria and exclusion criteria. There was therefore the possibility of bias by the inclusion and exclusion criteria and by referral of the patients by the ophthalmologists. Second, it was possible to include patients with simple myopic optic neuropathy without glaucoma. For differentiation of myopic optic neuropathy patients, by recognizing the defect of VF in fundus findings, including the optic nerve, we believe that the probability of a definitive glaucoma diagnosis is high. Thus, we diagnosed glaucoma with high myopia. Third, it is possible that some DHs may have occurred but regressed between each examination. Kitazawa et $\mathrm{al}^{37}$ reported that $92 \%$ of all DHs were present for at least 4 weeks, recurrences were seen in $64 \%$ of the eyes, and $92 \%$ of these occurred within 28 weeks following the previous hemorrhage. Examinations every 2 months in this study were therefore sufficient to detect the DH. Fourth, the mean follow-up period in this study was $>10$ years. During this period of time, lens opacity could have been affected by perimetries. ${ }^{44}$ However, because the enrolled corrected visual acuity cases were $>20 / 20$, it was thought that there was minimal influence from lens opacities. Moreover, we analyzed the patient data before performing cataract surgery.

\section{Conclusion}

Highly myopic glaucoma is considered to be a combination of myopic optic neuropathy and GON. We hypothesize that if GON is predominant, it has frequent DHs, which may cause more progression in VF losses. However, when the myopic optic neuropathy is predominant, it has less DHs and may result in less progressive VF loss.

\section{Acknowledgment}

This manuscript was edited by Edanz Group Ltd.

\section{Disclosure}

The authors report no conflicts of interest in this work.

\section{References}

1. Wu SY, Nemesure B, Leske MC; Barbados Eye Study Group. Refractive error s in a black adult population: the Barbados Eye Study. Invest Ophthalmol Vis Sci. 1999;40(10):2179-2184.

2. Mitchell P, Hourihan F, Sandbach J, Wang JJ. The relationship between glaucoma and myopia: the Blue Mountains Eye Study. Ophthalmology. 1999;106(10):2010-2015.

3. Weih LM, Nanjan M, McCarty CA, Taylor HR. Prevalence and predictors of open-angle glaucoma: results from the visual impairment project. Ophthalmology. 2001;108(11):1966-1972.

4. Wong TY, Klein BE, Klein R, Knudtson M, Lee KE. Refractive errors, intraocular pressure, and glaucoma in a white population. Ophthalmology. 2003;110(1):211-217.

5. Ramakrishnan R, Nirmalan PK, Krishnadas R, et al. Glaucoma in a rural population of southern India: the Aravind comprehensive eye survey. Ophthalmology. 2003;110(8):1484-1490.

6. Suzuki Y, Iwase A, Araie M, et al. Risk factors for open-angle glaucoma in a Japanese population: the Tajimi Study. Ophthalmology. 2006;113(9): 1613-1617.

7. Xu L, Wang Y, Wang S, Wang Y, Jonas JB. High myopia and glaucoma susceptibility: the Beijing Eye Study. Ophthalmology. 2007; $114(2): 216-220$.

8. Casson RJ, Gupta A, Newland HS, et al. Risk factors for primary openangle glaucoma in a Burmese population: the Meiktila Eye Study. Clin Experiment Ophthalmol. 2007;35(8):739-744.

9. Garudadri C, Senthil S, Khanna RC, Sannapaneni K, Rao HB. Prevalence and risk factors for primary glaucomas in adult urban and rural populations in the Andhra Pradesh Eye Disease Study. Ophthalmology. 2010;117(7):1352-1359.

10. Perera SA, Wong TY, Tay WT, Foster PJ, Saw SM, Aung T. Refractive error, axial dimensions, and primary open-angle glaucoma: the Singapore Malay Eye Study. Arch Ophthalmol. 2010;128(7):900-905.

11. Kuzin AA, Varma R, Reddy HS, Torres M, Azen SP; Los Angeles Latino Eye Study Group. Ocular biometry and open-angle glaucoma: the Los Angeles Latino Eye Study. Ophthalmology. 2010;117(9):1713-1719.

12. Fong DS, Epstein DL, Allingham RR. Glaucoma and myopia: are they related? Int Ophthalmol Clin. 1990;30(3):215-218.

13. Ohno-Matsui K, Shimada N, Tasuzumi K, et al. Long-term development of significant visual field defects in highly myopic eyes. Am J Ophthalmol. 2011;152(2):256-265. 
14. Yasuzumi K, Ohno-Matsui K, Yoshida T, et al. Peripapillary crescent enlargement in highly myopic eyes evaluated by fluorescein and indocyanine green angiography. Br J Ophthalmol. 2003;87(9):1088-1090.

15. Jonas JB, Budde WM. Optic nerve damage in highly myopic eyes with chronic open-angle glaucoma. Eur J Ophthalmol. 2005;15(1):41-47.

16. Kim TW, Kim M, Weinreb RN, Woo SJ, Park KH, Hwang JM. Optic disc change with incipient myopia of childhood. Ophthalmology. 2012; 119(1):21-26

17. La Torre G, Pacella E. Use of tablet, smartphone and myopia: where is the evidence? Senses Sci. 2014;1(3):82-83.

18. Smaldone G, Campagna O, Pacella F, et al. Computer use and onset of myopia in children: a systematic review. Senses Sci. 2015;2(1):1-7.

19. Jonas JB. Role of cerebrospinal fluid pressure in the pathogenesis of glaucoma. Acta Ophthalmol. 2011;89(6):505-514.

20. Yoshino T, Fukuchi T, Togano T, et al. Rate of progression of total, upper, and lower visual field defects in patients with open-angle glaucoma and high myopia. Jpn J Ophthalmol. 2016;60(2):78-85.

21. Yamada H, Akagi T, Nakanishi H, et al. Microstructure of peripapillary atrophy and subsequent visual field progression in treated primary open-angle glaucoma. Ophthalmology. 2016;123(3):542-551.

22. He M, Zheng Y, Xiang F. Prevalence of myopia in urban and rural children in mainland China. Optom Vis Sci. 2009;86(1):40-44.

23. Lam CS, Lam CH, Cheng SC, Chan LY. Prevalence of myopia among Hong Kong Chinese schoolchildren: changes over two decades. Ophthalmic Physiol Opt. 2012;32(1):17-24.

24. The Japan Glaucoma Society Guidelines for Glaucoma. (3rd ed). JJpn Ophthalmol Soc. 2012;116(1):3-46.

25. European Glaucoma Society. Terminology and Guidelines for Glaucoma. 4th ed. Savona: Dogma; 2014.

26. Pacella F, Mazzeo F, Giorgi D, et al. Giant cell arteritis. The importance of immediate and appropriate diagnosis and treatment for better prognosis. Case report. Clin Ophthalmol. 2012;6:909-913.

27. Doi H, Nakazawa T, Fuse N, Kato K. Changes in axial length in children measured by noncontact laser interference biometry. Jpn J Clin Ophthalmol. 2011;65(6):817-820.

28. Asakuma T, Tasuda M, Ninomiya T, et al. Prevalence and risk factors for myopic retinopathy in a Japanese population: the Hisayama Study. Ophthalmology. 2012;119(9):1760-1765.

29. Fukuchi T, Yoshino T, Sawada H, et al. Progression rate of total, and upper and lower visual field defects in open-angle glaucoma patients. Clin Ophthalmol. 2010;4:1315-1323.

30. Naito T, Yoshikawa K, Mizoue S, et al. Relationship between visual field progression and baseline refraction in primary open-angle glaucoma. Clin Ophthalmol. 2016;10:1397-1403.
31. Nitta K, Sugiyama K, Higashide T, Ohkubo S, Tanahashi T, Kitazawa Y. Does the enlargement of retinal nerve fiber layer defects relate to disc hemorrhage or progress visual field loss in normal-tension glaucoma? J Glaucoma. 2011;20(3):189-195.

32. Park HY, Hong KE, Park CK. Impact of age and myopia on the rate of visual field progression in glaucoma patients. Medicine (Baltimore). 2016; 95(21):e3500.

33. Drance SM, Fairclough M, Butler DM, Kottler MS. The importance of disc hemorrhage in the prognosis of chronic open angle glaucoma. Arch Ophthalmol. 1977;95(2):226-228.

34. Iwata K, Nanba K, Abe H. Typical slit-like retinal nerve fiber layer defect and corresponding scotoma. J Jpn Ophthalmol Soc. 1981;85(10): 1791-1803.

35. Airaksinen PJ, Mustonen E, Alanko HI. Optic disc hemorrhages. Analysis of stereophotographs and clinical data of 112 patients. Arch Ophthalmol. 1981;99(10):1795-1801.

36. Krakau T. Disc Hemorrhages-Forerunners of Chronic Glaucoma. Glaucoma Update II. Berlin: Springer; 1983:71-76.

37. Kitazawa Y, Shirato S, Yamamoto T. Optic disc hemorrhage in lowtension glaucoma. Ophthalmology. 1986;93(6):853-857.

38. Drance SM. Disc hemorrhages in glaucomas. Surv Ophthalmol. 1989; 33(5):331-337.

39. Daugeliene L, Yamamoto T, Kitazawa Y. Effect of trabeculectomy on visual field in progressive normal-tension glaucoma. Jpn J Ophthalmol. 1998;42(4):286-292.

40. Collaborative Normal-Tension Glaucoma Study Group. Comparison of glaucomatous progression between untreated patients with normaltension glaucoma and patients with therapeutically reduced intraocular pressures. Am J Ophthalmol. 1998;126(4):487-497.

41. Ishida K, Yamamoto T, Sugiyama K, Kitazawa Y. Disk hemorrhage is a significantly negative prognostic factor in normal-tension glaucoma. Am J Ophthalmol. 2000;129(6):707-714.

42. Iwase A, Suzuki Y, Araie M, et al; Tajimi Study Group, Japan Glaucoma Society. The prevalence of primary open-angle glaucoma in Japanese: The Tajimi Study. Ophthalmology. 2004;111(9):1641-1648.

43. De Moraes CG, Prata TS, Liebmann CA, Tello C, Ritch R, Liebmann JM. Spatially consistent, localized visual field loss before and after disc hemorrhage. Invest Ophthalmol Vis Sci. 2009;50(10):4727-4733.

44. Cavallotti C, Pacella E, Pescosolido N, Tranquilli-Leali FM, Feher J. Age-related changes in the human optic nerve. Can J Ophthalmol. 2002; 37(7):389-394.
Clinical Ophthalmology

\section{Publish your work in this journal}

Clinical Ophthalmology is an international, peer-reviewed journal covering all subspecialties within ophthalmology. Key topics include: Optometry; Visual science; Pharmacology and drug therapy in eye diseases; Basic Sciences; Primary and Secondary eye care; Patient Safety and Quality of Care Improvements. This journal is indexed on Submit your manuscript here: http://www.dovepress.com/clinical-ophthalmology-journal

\section{Dovepress}

PubMed Central and CAS, and is the official journal of The Society of Clinical Ophthalmology (SCO). The manuscript management system is completely online and includes a very quick and fair peer-review system, which is all easy to use. Visit http://www.dovepress.com/ testimonials.php to read real quotes from published authors. 